Kryatchenko O. B., Pechyborsch V. P., Yakimets V. M., Mazii S. I., Pechyborsch O. V., Yakimets V. V., Maidanyuk V. P., Yermuraki P. P. Laboratory and patient of kyiv city clinical emergency hospital. Journal of Education, Health and Sport. 2021;11(05): 158-165. eISSN 2391-8306. DOI http://dx.doi.org/10.12775/JEHS.2021.11.05.016

https://apcz.umk.pl/czasopisma/index.php/JEHS/article/view/JEHS.2021.11.05.016

https://zenodo.org/record/4948702

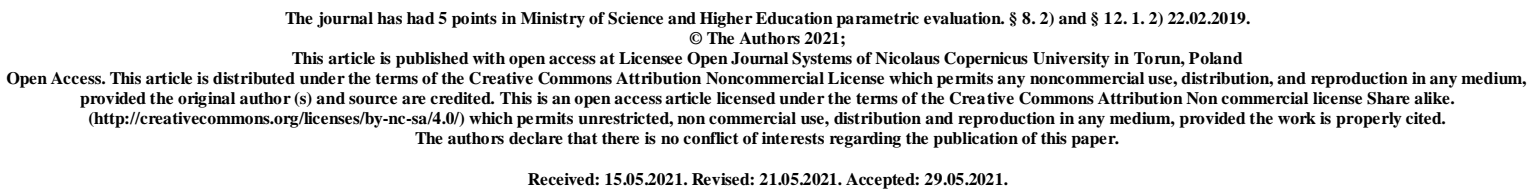

UDC 614.212 (477.87):614.253.1:616-082

\title{
LABORATORY AND PATIENT OF KYIV CITY CLINICAL EMERGENCY HOSPITAL
}

\author{
O. B. Kryatchenko ${ }^{1}$, V. P. Pechyborsch ${ }^{2}$, V. M. Yakimets ${ }^{2}$, S. I. Mazii ${ }^{2}$, \\ O. V. Pechyborsch ${ }^{3}$, V. V. Yakimets ${ }^{4}$, V. P. Maidanyuk ${ }^{5}$, P. P. Yermuraki ${ }^{5}$
}

${ }^{1}$ Kyiv City Clinical Emergency Hospital, Kyiv, Ukraine

${ }^{2}$ State Scientific Institution "Center for Innovative Medical Technologies of the National Academy of Sciences of Ukraine", Kyiv, Ukraine

${ }^{3}$ Main Military Medical Clinical Center (Central Clinical Hospital) of the State Border Guard Service of Ukraine, Kyiv, Ukraine ${ }^{4}$ Ukrainian Military Medical Academy, Kyiv, Ukraine ${ }^{5}$ Odessa National Medical University, Odessa, Ukraine

V. Maidanyuk - Orcid 0000-0002-3351-1515

\begin{abstract}
The aim of the work is to analyze the activities of the clinical diagnostic laboratory of the Kyiv City Clinical Emergency Hospital (hereinafter - KCCEH) in comparison with the hospitals of Kyiv for 2017-2018 and determine the role of existing mechanisms to optimize the activities of this laboratory.
\end{abstract}


The article uses the materials of statistical reports of KCCEH and treatment and prevention facilities of Kyiv for 2017-2018 using the method of systematic analysis of statistical materials, as well as systemic and structural-functional approaches.

Analysis of the main performance indicators of the clinical diagnostic laboratory of the Kyiv City Clinical Emergency Hospital shows that in 2018 compared to 2017 there is an increase of $2.9 \%$ in the absolute number of laboratory tests due to increased highly informative research and introduction of innovative technologies in diagnosis.

In the context of reforming the health care system under the conditions of social and economic crisis and our country's hybrid war, the only most appropriate way to optimize the laboratory department of the Kyiv City Clinical Emergency Hospital and similar hospitals in Ukraine is the centralization of clinical laboratory research and laboratory services.

\section{Keywords: Laboratory; Kyiv City Clinical Emergency Hospital; patient}

Introduction. The most valuable thing for a person is his or her health. But often people only really realize this when sudden traumas, poisonings, diseases or their exacerbation disrupt their plans. Timely diagnosis, which begins with basic tests, will help to learn about the disease at an early stage, and the treatment that follows will be much more effective.

In order to get an idea of the overall picture of the patient's health, the doctor must have accurate results of laboratory tests. Undoubtedly, this requires the prompt taking of the necessary material and its research, the use of high-quality laboratory reagents, the availability of the necessary modern equipment, and so on. A special role is played by the professional training of laboratory staff.

In this context, it is advisable to remind about the hard daily work of the KCCEH clinical diagnostic laboratory without any weekends and holidays.

For further reference: up to 100 injured, poisoned and patients with acute diseases and exacerbations of chronic ones are delivered to this hospital 24 hours a day by ambulances.

The aim of the study is to analyze the activities of the clinical diagnostic laboratory of the Kyiv City Clinical Emergency Hospital (hereinafter - KCCEH) in comparison with the hospitals of Kyiv for 2017-2018 and determine the role of existing mechanisms to optimize the activities of this laboratory.

\section{Materials and methods}


The article uses the materials of statistical reports of KCCEH and treatment and prevention facilities of Kyiv for 2017-2018 using the method of systematic analysis of statistical materials, as well as systemic and structural-functional approaches.

\section{Results and discussion}

In the Art. 49 of the Constitution of Ukraine it is stated that: "Everyone has the right to health care, medical assistance and medical insurance. Health care is provided by the state funding of relevant socio-economic, health care and health prevention programs.

The state creates conditions for effective and accessible medical care for all citizens. In ther state and municipal health care facilities, medical care is provided free of charge; the existing network of such establishments cannot be reduced. The state promotes the development of medical institutions of all forms of ownership [1].

Article 6 of the Law of Ukraine "Fundamentals of the Legislation of Ukraine on Health Care" stipulates: Every citizen of Ukraine has the right to health care...

Article 8 of the same Law interprets the following: The state recognizes the right of every citizen of Ukraine to health care and ensures its protection.

Every citizen has the right to receive free medical care in state and municipal health care institutions, which includes: ...emergency medical care...[2].

At the same time in the paragraph 1 of Art. 3 of the Law of Ukraine "On Emergency Medical Care" it is stipulated that in Ukraine every citizen of Ukraine and any other person has the right to free, affordable, timely and quality emergency medical care provided per this Law [3].

Thus, the legal framework of our state guarantees the right to free, affordable, timely and quality emergency medical care, but how is it done in the current conditions of our time, and what measures are taken by the Ministry of Health of Ukraine to meet the requirements of these important regulations? In this context, it is necessary to pay attention to the state of implementation of the requirements of Order №398 of the Ministry of Health of Ukraine dated 16.06.2014 "On approval of procedures for providing home care to persons in emergencies" [4]. Upon considering this vital issue, special attention should be paid to the most difficult and painful issue - the organization during the provision of emergency (urgent) medical care in the hospital in our country. The relevance of this issue is explained by the results of the analysis of the state of this important area of emergency medical care. 
Analysis of the state of the regulatory framework shows that Order № 96 of the Ministry of Health of Ukraine dated 19.02.2010 "Issues of organization of laboratory service" [5] provided the following:

In order to organize the laboratory service, improve the work of laboratories in Ukraine, provide scientific support for their work and training in laboratory work, in accordance with Art. 20 of the Law of Ukraine "Fundamentals of the legislation of Ukraine on health care" to develop a draft Concept of the State target program for the development of laboratory services for 2011-2016, providing in it, фтьщтп the introduction of laboratory information systems in the practice of clinical diagnostic laboratories developed in the Ministry of Health of Ukraine, but for unknown reasons was not implemented in the practice of health care facilities.

In accordance with the requirements of Articles 7, 14, 22 of the Fundamentals of Legislation of Ukraine on Health Care, pursuant to subparagraph 15 of paragraph 7 of section I of the Plan of basic organizational measures of the Ministry of Health of Ukraine for 2015 in order to create a perfect quality management system for clinical laboratory research and ensure uniformity of measurements in medical laboratories of Ukraine by Order №644 of the Ministry of Health of Ukraine dated 01.10.2015 the Concept of quality management system in medical laboratories of Ukraine in accordance with international standards and its Action Plan [6] was approved.

The experience of practitioners of primary health care, specialized and highly specialized medical care shows that up to $80 \%$ of the information needed to ensure the treatment and diagnostic process in countries near and far abroad is provided by medical laboratories and their importance in developed countries with each year has a steady upward trend. It is impossible to exaggerate the role of the clinical and diagnostic laboratory in the process of diagnosing a disease.

Such a role in the medical and diagnostic process of the laboratory can be guaranteed only if they meet their needs in the necessary means for quality, reliable research of biological material. But let us go back to a patient who has become acutely ill, poisoned or injured for one reason or another, and follow an algorithm to obtain reliable information to determine his health and diagnose the disease, poisoning or injury. Thus, the path of this patient is as follows:

Conducting general laboratory tests of blood and urine in Ukraine is available to everyone, in public clinics such tests are free. Of course, you have to stand in line or come in 
the morning, then you can get to the lab first. In a few days the tests will be ready. You can pick up the results at the clinic.

The same tests can be taken in a private medical laboratory, arriving at any convenient time. The results are sent by e-mail if it is convenient for the patient. But such tests are no longer free.

Quite often there is a need for these studies and other, more informative studies, in one case or another in an emergency in case of urgent conditions of patients, when the timely diagnosis depends on the lives of most patients and, consequently, to make a decision regarding further tactics.

In this context, it is advisable to analyze the main indicators of the clinical diagnostic laboratory of the Kyiv City Clinical Emergency Hospital according to the reports of 20172018. In 2018 an average of 3706 laboratory tests were performed daily, in 2017-3601, provided that the hospital operates without weekends and holidays. At the same time, if we analyze the work of the laboratory on average during each hour, the number in 2018 is 154.4 studies, and in $2017-150.0$.

Analysis of the intensity of the work of the clinical diagnostic laboratory during the day shows that from 60 to $70 \%$ of studies are conducted at night, given that the patients admitted to the hospital in most cases are delivered by ambulance.

The completeness and scope of the required research is carried out in accordance with the list of measurement capabilities (certificate of measurement capabilities №PT-№399/18, valid until 30.10.2020).

The vast majority of studies, due to the specifics of the hospital, are performed not in series, but individually and in citations.

The laboratory performs studies for incoming injured, poisoned, patients (Tables 1, 2) with acute diseases and exacerbations of chronic ones (up to 100 patients per day), for patients from intensive care units (4 intensive care units with 48 beds). In addition, citation studies in 18 clinical departments (average 50 to 60 studies per day).

Therefore, we can conclude that the number of studies in 2018 compared to 2017 increased by 38091 studies, which is $2.9 \%$, mainly due to an increase in the number of hightech and highly informative biochemical studies compared to 2017 - by 38,648 studies, which is $8.9 \%$, including an increase in the number of studies of enzymes - by $22.2 \%$, electrolytes by $0.62 \%$, coagulogram - by $3.9 \%$, general laboratory tests - by $0.47 \%$, microbiological - by 
$0.5 \%$. At the same time, the share in 2018 decreased, including: hematological - by $0.76 \%$, cytological - by $7.23 \%$, immunological - by $3.52 \%$.

Table 1

Analysis of indicators of laboratory tests of the clinical diagnostic laboratory of the Kyiv City Clinical Emergency Hospital for 2017-2018

\begin{tabular}{|c|c|c|c|c|c|c|c|c|c|c|}
\hline Year & Total & Clinical & $\begin{array}{c}\text { Hematolog } \\
\text { ical }\end{array}$ & $\begin{array}{c}\text { Cytolo } \\
\text { gical }\end{array}$ & $\begin{array}{c}\text { Micro- } \\
\text { biolo- } \\
\text { logical }\end{array}$ & $\begin{array}{c}\text { Immu- } \\
\text { nolo- } \\
\text { gical }\end{array}$ & $\begin{array}{c}\text { Bioche- } \\
\text { mical }\end{array}$ & Enzy-mes & Electro- \\
lytes & $\begin{array}{c}\text { Coagulo- } \\
\text { gram }\end{array}$ \\
\hline \multirow{2}{*}{2018} & 1352739 & 248656 & 485611 & 2166 & 34716 & 70953 & 510637 & 118848 & 34888 & 109379 \\
& 100,0 & 18,38 & 35,89 & 0,16 & 2,57 & 5,25 & 37,75 & 23,27 & 6,83 & 21,42 \\
\hline \multirow{2}{*}{2017} & 1314648 & 247505 & 489299 & 2617 & 34700 & 68538 & 471989 & 97272 & 34672 & 105284 \\
& 100,0 & 18,82 & 37,22 & 0,19 & 2,64 & 5,21 & 35,90 & 20,61 & 7,35 & 22,31 \\
\hline
\end{tabular}

Notes: there are quantitative indexes in the numerator, the absolute indexes ( $\%$ of the total number of studies, and biochemical studies) - in the denominator.

Table 2.

Indicators of laboratory tests per 1 patient according to reports for 2017-2018

\begin{tabular}{|c|c|c|c|}
\hline Year & $\begin{array}{c}\text { Number of studies } \\
\text { per year }\end{array}$ & $\begin{array}{c}\text { Number of studies per patient } \\
\text { discharged from the hospital }\end{array}$ & $\begin{array}{c}\text { Number of studies per } \\
\text { patient in Kyiv }\end{array}$ \\
\hline 2018 & 1352739 & 48.23 & 43.18 \\
\hline 2017 & 1314648 & 38.47 & 40.3 \\
\hline
\end{tabular}

If we analyze the share in the overall structure of indicators of laboratory tests of the clinical diagnostic laboratory, then in the first place there is the biochemical, and in the second - hematological studies, which are the most informative.

With the introduction of new modern methods and standards of examinations, the number of studies per patient discharged from the hospital also increased by $25.37 \%$ and exceeded the average for the city of Kyiv by $11.7 \%$.

The vast majority of patients are taken to the hospital by emergency (ambulance) crews and are admitted in critical condition, without the appropriate clinical examinations and concomitant severe cancer will be detected in the hospital during the examination. Evidence of this state of affairs is that only in 2018, 25 oncohematological patients (with acute and chronic leukemias) were detected for the first time in the hospital during examinations on admission and in the treatment of injured, poisoned, patients with acute diseases and exacerbation of chronic diseases. 
In the context of the workload and intensity of work, it is worth noting that the clinical diagnostic laboratory of the Kyiv City Clinical Ambulance carries out a large amount of work and according to statistical quantitative indicators ranks second among all medical institutions in Kyiv.

For further reference: only Oleksandrivska Hospital exceeds the provided indicators by $10 \%$ in terms of the number of studies. And if we consider the share of laboratory tests performed by the clinical diagnostic laboratory $\mathrm{KCCEH}$ in the total amount of laboratory tests performed in treatment and prevention facilities under the Department of Health of Kyiv, this figure is $5 \%$.

Analysis of the main performance indicators of the clinical diagnostic laboratory of the Kyiv City Clinical Emergency Hospital shows that in 2018 compared to 2017 there is an increase of $2.9 \%$ in the absolute number of laboratory tests due to increased highly informative research and introduction of innovative technologies in diagnosis.

Pursuant to Articles 5 and 10 of the Law of Ukraine "On Emergency Medical Care" in 2019, the hospital opened an emergency department instead of a reception department, which according to the experience of similar departments such as Emergency Department (ED) in hospitals of developed countries, to ensure the improvement of the organization of work on the diagnosis of the contingent of patients in emergencies and undoubtedly the organization of work and performance indicators of the clinical diagnostic laboratory [7].

As a result of a comprehensive analysis of the clinical diagnostic laboratory it was found that the wear of laboratory equipment is $40 \%$; there is no system in providing equipment, the diagnostic process is provided by $90-95 \%$ of the required examination and treatment protocols; the use of manual and automated research methods does not allow to optimize the reagent base; manual research methods make up $80 \%$ of testing in the diagnostic process; the absence of a contract for permanent service complicates the timely repair and adjustment of equipment.

And, despite the fact that the country is in a state of hybrid war, there are a number of organizational issues that need to be addressed urgently.

\section{Conclusions}

1. In the context of reforming the health care system in a social and economic crisis and our country's hybrid war, the only most appropriate to optimize the laboratory department of the Kyiv City Clinical Emergency Hospital and similar hospital departments in Ukraine is the centralization of clinical laboratory research and laboratory services. Centralization allows 
efficient and rational use of limited resources of the industry and to ensure the efficient use of modern laboratory equipment, to promote the implementation of international standards to ensure the proper quality of laboratory research.

2. Given the experience of developed countries, the process of optimizing the laboratory department of the Kyiv City Clinical Ambulance and similar hospitals in Ukraine is based primarily on the systematic implementation of emergency departments/rooms of the ED type, instead of existing admission departments, an important element of which is a systematic reform of the staff structure, unification of specialization and level of professional training of medical staff, technical re-equipment and reconstruction of premises of all $\mathrm{KCCEH}$ departments, in order to ensure the process of emergency care treatment of patients that is qualitatively and economically feasible by the best world standards.

\section{References}

1. Constitution of Ukraine (Vidomosti Verkhovnoi Rady Ukrainy (VVR), 1996, № 30, page 141) with changes and additions. (For the official interpretation of the provisions of part three of Article 49, see the Decision of the Constitutional Court № 10-rp/2002 dated 29.05.2002\} [in Ukrainian].

2. Law of Ukraine "Fundamentals of Legislation of Ukraine on Health Care", 19.11.1992 № 2801-XII (Vidomosti Verkhovnoi Rady Ukrainy (VVR), 1993, № 4, page 19) with changes and additions [in Ukrainian]

3. Law of Ukraine "On Emergency Medical Care" dated 05.07.2012 № 5081-VI (Vidomosti Verkhovnoi Rady, 2013, № 30, p.340) [in Ukrainian].

4. Order № 398 of the Ministry of Health of Ukraine dated 16.06.2014 "On approval of procedures for providing home care to persons in emergencies." Registered in the Ministry of Justice of Ukraine on 07.07.2014 by № 750/25527 [in Ukrainian].

5. Order №96 of the Ministry of Health of Ukraine dated 10.02.2010 "Issues of organization of laboratory service" [in Ukrainian].

6. Order №644 of the Ministry of Health of Ukraine dated 01.10.2015 "On approval of the Concept of quality management system in medical laboratories of Ukraine in accordance with the requirements of international standards and the Action Plan for its implementation" [in Ukrainian].

7. Law of Ukraine №5081-VI. "On Emergency Medical Care" dated 05.07.2012 [in Ukrainian]. 